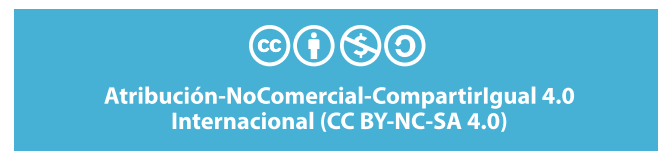

DOI: http://dx.doi.org/10.20983/reij.2022.1.1
Mauro Pérez Bravo ${ }^{1}$

FECHA DE RECEPCIÓN: 15 de junio 2021

FECHA DE ACEPTACIÓN: 27 de agosto 2021

\title{
EL EXILIO EN MÉXICO: UN VACÍO JURÍDICO
}

\author{
Exile in Mexico: a legal void
}

\section{Resumen:}

México ha implementado acciones legislativas con el objetivo de atender diferentes facetas de la movilidad humana (migración, desplazamiento forzado), sin embargo, consideramos que el exilio, como una faceta más, no se encuentra tan visibilizado o atendido en legislaciones sobre derechos humanos. Ya sea por las reducidas bases de datos, estudios o testimonios, el exilio carece de un ordenamiento legal especial, incluso, no hemos terminado de conocerlo y entenderlo conceptualmente, lo que deviene en una confusión con otros términos como asilo, refugio o destierro. Por lo anterior, la pregunta que desarrollaremos a lo largo del presente ensayo es: ¿es necesaria una legislación especial para atender a las personas en situación de exilio en México? Con lo que podremos plantear el debate jurídico sobre el exilio en México con una metodología analítica sobre las leyes e información disponible, además de una metodología comparada auxiliándonos de legislaciones internacionales. De esta manera, propondremos algunas bases para el desarrollo de una propuesta legislativa sobre el exilio en México.

Palabras clave: exilio, legislación, derechos humanos, asilo, refugio, violaciones a derechos humanos.

\begin{abstract}
:
Mexico has implemented public policies with the aim of addressing different facets of human mobility (migration, forced displacement), however, we consider that exile, as another facet, is not as visible or addressed in public policies on human rights. Either due to the reduced databases, studies or testimonies, the exile does not have a special legal order, we have not even finished knowing it and understanding it conceptually, which results in a confusion with other terms such as asylum, refuge or exile. Therefore, the question that

1 Doctorando de la Facultad de Derecho de la Universidad Nacional Autónoma de México. Correo electrónico: mauro050@yahoo.com.mx. ORCID: https://orcid.org/0000-0002-9303-4730.
\end{abstract}


we will develop throughout this essay is: is special legislation necessary to attend to people in exile in Mexico? With which we can raise the legal debate on exile in Mexico with an analytical methodology on the laws and available information, as well as a comparative methodology using international legislation. In this way, we will propose some bases for the development of a legislative proposal on exile in Mexico

Key words: exile, legislation, human rights, asylum, refuge, human rights violations.

\section{Introducción}

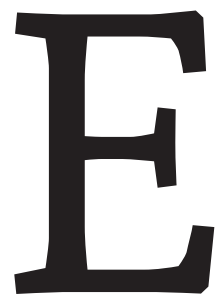

l gobierno de México ha implementado políticas públicas con el objetivo de atender diferentes facetas de la movilidad humana como lo son la migración en tránsito; solicitantes del reconocimiento de la condición de refugiado; víctimas de desplazamiento forzado interno; personas retornadas; niñas, niños y adolescentes migrantes no acompañados, por mencionar algunas. Esto se debe en gran medida a que existe un fuerte y sólido marco jurídico que fundamenta las políticas públicas para la atención de estos grupos de personas en situación de vulnerabilidad. Ahora bien, ¿qué pasa con las personas en situación de exilio que están o han estado en México? Y es esta la pregunta principal que se va a discutir: ¿cuál es la situación jurídica actual de las personas en situación de exilio?

Desde los puntos de vista sociológico, político, ético, filosófico o histórico, el exilio puede ser considerado como una vertiente más de la movilidad humana con sus propias característica y particularidades. Sin embargo, en México no se encuentra tan visibilizado como la migración en tránsito, el desplazamiento forzado interno, o como las personas solicitantes del reconocimiento 
de la condición de refugiado, ya sea por las reducidas bases de datos, estudios, testimonios, o por las coyunturas políticas y éticas en la definición de 'exilio'.

En el presente estudio se reflexiona sobre la normatividad aplicable a las personas en situación de exilio, para con ello detectar los alcances y los límites de las legislaciones pertinentes, desde una perspectiva de los derechos humanos que permita proponer alternativas jurídicas para consolidar las bases de políticas públicas contemporáneas que atiendan esta vertiente de la movilidad humana.

Se parte del supuesto de que en México no existe claridad conceptual ni jurídica sobre el exilio. Las políticas públicas en materia de movilidad humana están encaminadas a atender, por ejemplo, a personas solicitantes del reconocimiento de la condición de refugiado y solicitantes de asilo político, pero no alcanzamos a distinguir que exista una política pública específica para las personas que se encuentran en una situación de exilio. Entonces, son dos las hipótesis que planteamos en el presente trabajo: 1) no existe legislación aplicable que prevea la atención a personas en situación de exilio y, 2) no existe dicha legislación, porque no hemos podido comprender todo el contenido político, ético, histórico y, sobre todo, jurídico del exilio.

Las preguntas secundarias que queremos desarrollar en este trabajo son: ¿es necesaria una legislación para atender a las personas en situación de exilio en México? ¿Existe algún registro para atender a las personas en situación de exilio?

La estructura de este ensayo quedó conformada de la siguiente manera: primeramente, problematizaremos el concepto de 'exilio'. Posteriormente, expondremos nuestra propuesta conceptual, desde el ámbito jurídico, sobre lo que consideramos puede ser el exilio. Finalmente, llevaremos la reflexión sobre el exilio al plano jurídico nacional, para esto, y a fin de contar con un contexto más amplio, ahondaremos brevemente en algunos ejemplos de legislaciones que han tratado de atender a las personas en situación de exilio, en este caso tomaremos como referencia a España, Chile y Argentina, por ser países que históricamente han vivido situaciones de exilio y cuyas consecuencias todavía resienten, y de esta manera, analizaremos y discutiremos la posibilidad de una reforma legislativa mexicana que provea la atención a personas en situación de exilio.

\section{El exilio: para un acercamiento concep- tual}

La movilidad humana es todo un conglomerado de situaciones, conceptos y perspectivas que involucran disciplinas como el derecho, la demografía, la sociología, la historia, por mencionar algunas. Desde la investigación y la academia, para com- 
prender y proponer políticas públicas en la materia, se entiende que la movilidad humana tiene diversas facetas o vertientes. Existen diferencias entre la migración en tránsito, desplazamiento forzado interno, solicitantes del reconocimiento de la condición de refugiado, solicitantes de asilo, destierro, etcétera.

Consideramos de suma importancia que el Estado, como ente público con la encomienda de defender, garantizar y promover los derechos humanos de todas las personas, de conformidad con el Artículo 1 de la Constitución Política de los Estados Unidos Mexicanos (CPEUM), pueda atender estas diferencias conceptuales, y de esta manera, aplicar el ordenamiento legal para ejecutar las políticas públicas adecuadas.

Sin una clara base conceptual que nos permita tener especificidad en el manejo de los términos podemos caer en errores de aplicación jurídica, procedimientos administrativos o ineficacia en la ejecución de las políticas públicas. De aquí la importancia de ahondar, discutir y proponer acercamientos conceptuales y epistemológicos sobre determinadas problemáticas.

En el presente apartado se realizará una breve reflexión sobre el concepto de 'exilio', donde desarrollaremos algunos presupuestos teóricos, epistémicos, históricos y jurídicos a fin de contar con un panorama sobre este.
El objetivo en este primer apartado es problematizar el concepto de 'exilio' y ahondar en las coyunturas de su semántica. Asimismo, se buscará proporcionar las bases teóricas para tener mayor claridad en dicho concepto, en relación con otros como el de refugio o asilo político y así contar con un mejor manejo en el uso de los términos en el campo del derecho. De esta forma, se estudiará la posibilidad de proponer un marco normativo específico para la protección de los derechos humanos de las personas que se encuentren en situación de exilio.

El concepto de exilio tiende a confundirse con el de asilo político, refugio o destierro, debido a las similitudes que se encuentran en las causas que originan estas vertientes de la movilidad humana. Aunque en el presente ensayo no se tiene como objetivo ahondar en las particularidades entre refugio y asilo, mencionaremos unas breves ideas sobre los mismos, toda vez que es importante entenderlos y comprenderlos de manera general a fin de poder distinguirlos claramente.

Hannah Arendt escribió un texto profundamente emotivo, además de filosófico, en donde reflexiona sobre "los refugiados”. Ella misma señala la evolución del concepto: "Un refugiado solía ser una persona obligada a buscar refugio por algún acto cometido o por sostener alguna opinión política (...). Ahora 'refugiados' son aquellos de nosotros que han tenido 
la desgracia de llegar a un país nuevo sin medios y que han tenido que recibir ayuda de comités de refugiados” (2017, pág. 15). Arendt esboza toda una teoría ética y política sobre los refugiados, fruto de sus reflexiones en un contexto posterior a la Segunda Guerra Mundial. La teoría ética y política de Hannah Arendt es una crítica a los totalitarismos originados por la crisis del modelo político de gobierno basado en el binomio Estado/nación, en donde ya las personas comenzaban a perder derechos. Es Arendt quien construye uno de los postulados más conocidos en las discusiones sobre filosofía de los derechos humanos: el derecho a tener derechos.

Es la misma Arendt quien pone a discusión el concepto de 'refugiado', incluso, pareciera que ella misma no está conforme con el término y quiere entender lo que hay detrás del concepto de 'refugio': “Una de las cosas que sorprende es que ya en la primera línea de esta obra Arendt rechaza la etiqueta de 'refugiada' para describir su condición política actual” (Straehle, 2018, pág. 65). De entrada, para Arendt, salir del país de origen (por las razones que sean) es una condición política en primer lugar. Encontrarse en una situación de refugio, asilo o exilio, antes que una condición jurídica, es una política. Arendt ahonda en las implicaciones y consecuencias que devienen por tener que vivir obligadamente fuera del país de origen: "Lo que Arendt juzgaba como una situación inédita no era el hecho de tener que vivir en el exilio y de estar forzado a tener que abandonar sus hogares, una experiencia que se había repetido en Europa por lo menos desde las lejanas guerras de religión, sino la imposibilidad de hallar uno nuevo" (Straehle, 2018, pág. 66). En estas líneas el autor refiere que Arendt vive en una situación de exilio, aunque no podemos deducir que se esté hablando también de 'refugio' en un uso indistinto de los términos. No obstante, estas breves reflexiones ayudarán para adentrarse en el contenido de lo que se entiende como persona solicitante del reconocimiento de la condición de refugiado, y vislumbrar que existe toda una perspectiva más allá de lo meramente legal.

'Refugiados', tal y como lo hemos visto en Arendt, no es solamente un concepto jurídico que podemos ubicar en alguna normatividad en la materia, implica todo un esbozo histórico que recoge elementos éticos, políticos, sociológicos, etcétera. Las reflexiones sobre filosofía política de Hannah Arendt dan cuenta de ello.

Ahora bien, en mucha de la literatura jurídica internacional parecería que no hay claridad en el uso de conceptos como 'refugio' y 'asilo', y podríamos confundirnos en su partes sustantivas y procedimentales. Sin embargo, tanto el refugio como el asilo tienen naturaleza jurídica propia. Por ejemplo, el Manual y Directrices sobre Procedimientos y Criterios para determinar la Condición de Refugiado, del 
Alto Comisionado de las Naciones Unidas para los Refugiados (ANCUR), recoge definiciones de instrumentos internacionales sobre la calidad de refugiados. No obstante, también señala: "El Manual no se ocupa de cuestiones estrechamente relacionadas con la determinación de la condición de refugiado, como por ejemplo, la concesión de asilo a los refugiados" (Alto Comisionado de las Naciones Unidas para los Refugiados, 2011, pág. 8). Se puede entender entonces que el asilo es diferente al refugio. El asilo es un tipo determinado de protección que el Estado otorga a una persona, ya sea solicitante del reconocimiento de la condición de refugiado o no.

Desde el planteamiento que nos presenta el manual del ACNUR podemos inferir que una persona asilada política puede ser también reconocida con la condición de refugiada, pero una persona reconocida con la condición de refugiada no necesariamente puede ser asilada política:

La aceptación de una persona como asilado territorial no la transforma automáticamente en refugiado a los efectos de la Convención de 1951 y del Protocolo de 1967, pero sin duda constituye un elemento de juicio importante a considerar por las autoridades que deben calificar el refugio político. Y a la inversa, la calificación de una persona como refugiado político, según el Sistema de Naciones Unidas, no significa que, ipso iure, deba ser considerada como asilado territorial (Alto Comisionado de las Naciones Unidas para los Refugiados, 2011)

Hay quienes consideran que tanto el asilo como el refugio guardan la misma esencia y protección jurídica, pero la diferencia radica en que el asilo tiene como base el Sistema Interamericano de Derechos Humanos y el refugio encuentra su estructura en el Sistema de Naciones Unidas. Esta discusión, sin embargo, no parece tener sólidas bases jurídicas y argumentativas, según lo afirma Hope Hanlan (Leonardo Franco (Coord.), 2004, pág. 15).

Por su parte el doctor Miguel Carbonell distingue el refugio del asilo con el siguiente planteamiento: " $\mathrm{El}$ asilo se puede solicitar por persecuciones basadas en cuestiones políticas, mientras que en el caso del refugio se deben argumentar causas de carácter humanitario" (Carbonell, 2012, pág. 101). Empero, en el caso de México, la Ley sobre Refugiados, Protección Complementaria y Asilo Político, señala que el asilo político es la "Protección que el Estado Mexicano otorga a un extranjero considerado perseguido por motivos o delitos de carácter político”, en cambio, la condición de refugiado es el "Estatus jurídico del extranjero que encontrándose en los supuestos establecidos en el artículo 13 de la Ley, es reconocido como refugiado". Estos supuestos que menciona la ley son: temores fundados a ser perseguido por 
motivos de raza, religión, nacionalidad u opiniones políticas; que ha huido de su país de origen porque su vida se encuentra amenazada, entre otros supuestos. Como se puede apreciar, el componente político se encuentra tanto en el asilo político como en la condición de refugiado, por lo que, contrario a lo que plantea el doctor Carbonell, no es tan sencilla la distinción entre asilo y refugio.

De acuerdo con la ley, la diferencia más clara que se tiene para distinguir ambas categorías es que el solicitante de asilo realiza su trámite ante la Secretaría de Relaciones Exteriores, y el solicitante del reconocimiento de la condición de refugiado lo hace ante la Secretaría de Gobernación. Lo que sí se puede afirmar es que, en el sistema jurídico mexicano, el asilo siempre será por cuestiones políticas, pero no necesariamente se argumentarán cuestiones políticas para solicitar el reconocimiento de la condición de refugiado.

La discusión sobre las especificidades entre asilo y refugio tienen muchas más aristas y complejidades, empero, con el planteamiento general del problema, consideramos que podemos diferenciar ya el refugio del asilo. Una vez que se ha tenido mayor claridad conceptual, se pasará al estudio propiamente de 'exilio', y las diferencias con los primeros.

Aunque no precisa fecha o algún acontecimiento histórico que permita afirmar cuándo realmente empezó la historia del exilio, Norma Beatriz Martínez señala que el exilio nació en Grecia, y que su significado etimológico es: "aquello que no puede ser capturado, porque subyace la idea de lugar inviolable” (2012, pág. 203). Se podría incluso remitir a las metáforas sobre la historia de la humanidad y acudir las grandes explicaciones sobre el origen del mundo, por ejemplo, en términos bíblicos, la expulsión de Adán y Eva del Paraíso terrenal podría haber sido el primer exilio del que se tenga registro en la memoria colectiva de la cultura occidental. Lo que se quiere decir es que el exilio es tan antiguo como la historia de la humanidad misma, como una de las múltiples facetas de la movilidad humana.

$\mathrm{Al}$ igual que con 'refugio' y 'asilo', detrás de 'exilio' existe toda una serie de componentes históricos, religiosos, filosóficos, políticos y jurídicos, que nos proporcionan líneas tan diversas como complejas para entenderlo. Agamben sí alcanza a diferenciar los términos y señala que tanto los refugiados como los exiliados y los apátridas constituyen el ejemplo de la crisis por la que atraviesa el modelo Estado/nación en el sentido de que estas "vidas nudas" como él lo plantea, vienen a irrumpir en un sistema jurídico ideado para mantener las estructuras sociales e institucionales (Agamben, 1996).

Se puede asumir entonces que una primera característica del exilio es la "irrupción”, no como desestabilizador, sino 
como un elemento disruptivo, que rompe, que penetra, pero que quiere que las cosas funcionen, para que funcionen para él. Es decir, las personas en situación de exilio, o los exiliados, no quieren ni pretenden desestabilizar ningún sistema de gobierno, quieren entrar en la dinámica institucionalizada y funcionar en la maquinaria social a la cual llegan.

El refugiado puede retomar su identidad, su ser en el lugar en el que se encuentra; el exiliado no. El exiliado pierde su identidad, su lugar en el mundo, porque no hay un lugar para la persona exiliada, se ubica en un continuo vaivén ontológico y jurídico. Sin embargo, a diferencia del refugio o del asilo, no hay los suficientes esfuerzos a nivel internacional ni nacional, para dotar de un cuerpo normativo que permita sentar las bases para la atención de personas que se encuentran en situación de exilio.

En la antigua Roma, para las personas sentenciadas el exilio era una opción a tomar en lugar de alguna otra penalidad o castigo, es decir, podía ser considerado como una alternativa a una sanción o para evitar la sanción misma, aunque en este aspecto habrá que insistir que de cualquier forma, el exilio continuaba siendo una sanción: "un uso respecto del cual la actuación del exiliado se puede entender como ejercicio de un derecho, o como un medio para evitar un pena, o como pena que a partir de cierto momento se inserta en el sistema punitivo romano" (Torres
Aguilar, 1994, pág. 721). Si se toma el contexto histórico de la antigua Roma, entonces el exilio era un derecho otorgado a la persona sentenciada para conmutar su pena.

La figura del exilio ha transitado en su constitución y contenido conforme el paso de los años, sin embargo, la discusión ha versado principalmente desde el plano ético, político e histórico, no así desde el jurídico. A diferencia de lo que se planteaba en la antigua Roma, consideramos que no existe como tal el "derecho al exilio". Agamben plantea la problemática de esta manera:

El exilio es refugium, a saber: ni derecho ni pena. ¿Significa esto que es una situación de hecho, desligada de todos los sentidos del derecho? La hipótesis que quiero exponer es la siguiente: si el exilio parece rebasar tanto el ámbito luminoso de los derechos como el repertorio sombrío de las penas y oscilar entre el uno y el otro, ello no se debe a una ambigüedad inherente a él, sino que se sitúa en una esfera -por decirlo así- más originaria, que precede a una división y en la que convive con el poder jurídico-político. Esta esfera es la de la soberanía, del poder soberano (Agamben, 1996, pág. 12).

Agamben argumenta que una persona en situación de exilio se encuentra en un umbral intermedio entre la pena y el dere- 
cho, es un extraño y excluido, que no logra entrar a una nación/Estado, a diferencia de alguien que solicita el reconocimiento de la condición de refugiado, el cual puede ser recibido e incluido en el país de acuerdo con las normas y las leyes y estándares internacionales. Pero, esta exclusión de las personas en situación de exilio de las normas nacionales, ¿es debido a la condición misma de la persona o de que no existe en el imaginario epistemológico del derecho un esfuerzo por abrir el rubro que pueda incluir a una persona en situación de exilio, tal y como se hizo en su momento con el refugio y el asilo?

Agamben sostiene que el sentido del exilio es un devenir entre el derecho y la pena, sin embargo, desde de la base del derecho, consideramos que el exilio es una situación de expulsión de un territorio, es decir, es una "violación a los derechos humanos" (Gianoglio Pantano, 2012). En efecto, el exilio no es una pena o un derecho, pero tampoco es devenir constante. No obstante, la reflexión de Agamben, para algunos autores, existe una claridad muy explícita sobre el carácter punitivo del exilio: "En todo caso, lo que interesa remarcar aquí es que el exilio es antes que nada una pena. El carácter de penalidad expone claramente los vínculos de la práctica exiliar con el ámbito jurídico" (Cecilia Ávila, 2018, pág. 73). Para la autora es claro que su propuesta consiste en entender el exilio como una pena. Empero, nuestra propues- ta es identificar al exilio no solo como una pena, sino como una violación sistemática a los derechos humanos de una persona, lo que puede incluir una pena, un castigo o una condena del Estado.

Por lo anterior, se abandona la idea de entender al exilio como un derecho o únicamente como una penalidad, pero tampoco como lo plantea Agamben en el sentido de que es un devenir entre los dos primeros. Desde nuestra perspectiva, es oportuno entender el exilio como una violación a los derechos humanos de parte del Estado hacia una persona.

Actualmente, pensar en el exilio como un derecho o como una opción ante una condena o sentencia, supondría una visión alejada de una perspectiva de los derechos humanos. Se considera que no existe ni podría existir jamás como tal un "derecho al exilio", ya que una de las características del exilio es su carácter obligatorio, es decir, no existe una alternativa al mismo, "tiene el carácter de obligatoriedad, pues las personas son compelidas de manera inminente a abandonar su país de origen por tiempo indefinido. En el plano conceptual, el exilio es uno de los tantos mecanismos de represión utilizado por gobiernos de corte autoritario para impedir el cumplimiento y la influencia de proyectos políticos" (Norambuena, 2008, pág. 166). Este mecanismo de represión trae consigo la ruptura de proyectos personales, como también señala Norambuena, en donde la 
persona se encuentra una fractura en su desarrollo personal, político, cívico, ciudadano, y nosotros agregaríamos, en el ejercicio de sus derechos fundamentales.

\section{El exilio como una violación a los dere- chos humanos}

Si queremos entender el exilio como violación a los derechos humanos, se tendrá que plantear primeramente la siguiente interrogante: ¿qué es una violación a los derechos humanos? Una violación a los derechos humanos se da cuanto "el Estado, en cualquiera de sus niveles (federal, estatal o municipal) y poderes (ejecutivo, legislativo o judicial) incumple sus obligaciones de respetar, proteger, garantizar y promover" (Centro de Derechos Humanos, Miguel Agustín Pro Juárez, A.C., 2018, pág. 6) esos mismos derechos, de conformidad con el artículo 1 de la CPEUM. Por su parte, en la Ley General de Víctimas, artículo 6, fracción XXI, se define a la "violación a los derechos humanos” como:

Todo acto o omisión que afecte los derechos humanos reconocidos en la Constitución o en los Tratados Internacionales, cuando el agente sea servidor público en el ejercicio de sus funciones o atribuciones o un particular que ejerza funciones públicas. También se considera violación de derechos humanos cuando la acción o omisión referida sea realizada por un particular instigado o autorizado, explícita o implícitamente por un servidor público, o cuando actúe con aquiescencia o colaboración de un servidor público.

Las violaciones a los derechos humanos, entonces, se concretizan por acción u omisión de las autoridades.

Como se apuntó con anterioridad, el exilio es una acción del Estado, una penalidad propiamente hacia una persona, pero no una pena que surja de un ordenamiento legal que se aplique por la comisión de un delito, es decir, no existe algún delito en la actualidad que tenga como sanción el exilio. No obstante, la naturaleza de este es punitiva y sancionadora, la cual busca afectar la esfera jurídica de la persona.

Hemos precisado que tanto el refugio como el asilo son mecanismos de protección internacional y nacional que se le dan a una persona que se encuentra en una situación de vulnerabilidad determinada. El exilio, por el contrario, es una violación sistemática y contundente a los derechos humanos de esa persona. ¿Qué derechos humanos se ven afectados en una situación de exilio? Se verán a continuación.

En una situación de exilio existen violaciones a derechos humanos que podemos identificar de manera más explícita: el derecho a la vida, derecho a la libertad de expresión, derecho a la libertad de tránsito y residencia, principio de legalidad, derecho de acceso a la justicia, por mencionar al- 
gunos. Empero, en los siguientes párrafos ahondaremos en al menos tres derechos humanos que se ven afectados en situaciones de exilio pero que son derechos cuya violación podría ser más complicada de detectar o documentar en procesos jurisdiccionales o ante autoridades administrativas.

Un derecho humano que se viola sistemáticamente en el exilio es el derecho a la información. ¿Qué es el derecho humano a la información?: “Tu derecho de acceso a la información comprende el libre acceso a la información plural y oportuna, a poder solicitar, investigar, difundir, buscar y recibir cualquier información" ("Derecho humano de acceso a la información”, 2015, p.10). Si se acepta que una de las causas del exilio han sido los gobiernos encabezados por juntas militares, principalmente en algunos países de latinoamérica, la consecuencia de la política militar de estas juntas de gobierno, en la mayoría de los casos, fue la desaparición forzada a las personas disidentes. Es común leer experiencias de desapariciones forzadas atribuibles a gobiernos militares. La experiencia del exilio estaba ligada indudablemente a regímenes dictatoriales y represivos: "Las olas de exiliados no salían solamente de Bolivia sino de la mayoría de los países latinoamericanos, ya que éstos simultáneamente se encontraban sumergidos en regímenes dictatoriales" (Grinsvall \& Lora Fuentes, 2012, pág. 174). Existe sólida documen- tación sobre desapariciones forzadas en gobiernos militares, y personas exiliadas que salían de su país en busca de protección. Quienes lograron salir de los países gobernados por juntas militares, terminaron en el exilio, y quienes no pudieron hacerlo, fueron encarcelados o en su caso, víctimas de desaparición forzada. Este es el vínculo entre exilio y desapariciones forzadas.

Las personas exiliadas vieron afectado su derecho a la información, ya que no podían acceder a datos, informes o algún otro indicio sobre personas o familias que dejaban en su país de origen. Toda información se encontraba restringida para las personas en situación de exilio. De aquí la importancia del derecho de acceso a la información a fin de poder contar con los datos, flujos, nombres, registros, que permitan mantener certeza sobre las personas que se encontraban en situaciones de violaciones a derechos humanos en gobiernos dictatoriales, es decir, mantener en la memoria histórica los hechos antes, durante y después del exilio.

En estrecha relación con el derecho a la información, encontramos el derecho a la verdad, ¿qué es?:

Las víctimas de graves violaciones a los derechos humanos y del derecho internacional humanitario, así como sus familiares, tienen derecho a un recurso efectivo. Esto implica el derecho a saber 
la verdad acerca del abuso que han sufrido, incluyendo la posibilidad de identificar a los perpetradores, las causas que originaron tales violaciones y, de ser el caso, la suerte final o el paradero de las personas desaparecidas de manera forzada (Abrao, Mersky, Meregali, Morin, \& Rice, 2013, pág. 13).

El derecho a la verdad implica conocer todos los elementos que originaron el exilio, desde los actores que lo originaron hasta las causas con las cuales el Estado como agente persecutor llevó a imponer o crear las condiciones para el exilio de las personas. El ejercicio de este derecho, no obstante, está supeditado a una cuestión toral: ¿quién debe garantizar el derecho a la verdad? El Estado. Este mismo Estado que permitió las condiciones de violaciones y afectaciones a los derechos humanos en una situación de exilio, será el mismo que ahora se encargue de velar porque las víctimas tengan un efectivo acceso a la verdad. Esta doble dimensión del Estado como garante de los derechos humanos y a la vez como agente persecutor ya ha sido planteada en múltiples problemáticas sobre violaciones a derechos humanos, como es el caso de Colombia. Por un lado, se tiene que el Estado tiene el deber constitucional de proteger a sus ciudadanos, pero, además, tiene la facultad exclusiva del uso de la fuerza, es decir, una facultad punitiva sancionadora (Petro González \& Naranjo Tabares, 2020).

El derecho a la verdad en una situación de exilio contiene esta dificultad planteada en el párrafo antecedente, ya que el Estado, quien debería ser el garante de los derechos humanos de las personas, es a la vez, el agente persecutor que impone sanciones y destierra a las mismas, para llevarlas a una situación de exilio. Además, la persona en situación de exilio ya no se encuentra en su país de origen, ¿cómo exigir el derecho a la verdad desde el exilio? Una ruta que se puede seguir para exigir a los Estados las garantías necesarias para acceder al derecho a la verdad, pueden ser los mecanismos internacionales de protección a los derechos humanos. No han sido pocas las ocasiones en las que víctimas de violaciones a derechos humanos han acudido a estos mecanismos, como puede ser el Sistema Interamericano de Derechos Humanos, a fin de hacer efectivo el derecho a la verdad (Amaya Villarreal, 2007).

Finalmente, queremos puntualizar que las personas en situación de exilio ven mermado uno de los derechos que fue planteado por Hannah Arendt de la siguiente manera: "el derecho a tener derechos”. ¿A qué se refería Arendt? Se vuelve pues un momento a los planteamientos filosóficos realizados por Hannah Arendt sobre el derecho y los desplazamientos. 
Al principio de este trabajo, se acudió a las reflexiones de esta filósofa por su aporte a la discusión sobre la categoría política y ética sobre el refugiado. En estas se encuentran sus ideas sobre una línea argumentativa en relación con el despojo de los derechos que hacen los gobiernos totalitarios a los refugiados, desplazados, asilados, y nosotros diríamos, a los exiliados. El derecho a tener derechos deviene de una gran reflexión sobre los totalitarismos en la Europa de su contexto, además de la influencia de la filosofía kantiana en su pensamiento.

Se verá brevemente entonces, qué se puede entender por la frase "el derecho a tener derechos" y cómo se podría aplicar a las personas en situación de exilio:

El derecho a tener derechos, desde su punto de vista, trasciende las contingencias del nacimiento que nos diferencian y diferencian el uno del otro. El derecho a tener derechos puede realizarse solo en una comunidad política en la que se nos juzga no por las características que nos definen por nacimiento, sino por nuestras acciones y opiniones, por lo que hacemos y decimos y pensamos (Benhabib, 2004, pág. 50).

Arendt es clara en su planteamiento: lo que nos hace iguales es la comunidad política. Es en una comunidad en donde se puede ver realizado este ideal de la igualdad entre seres humanos:

La igualdad, en contraste con todo lo que está implicado en la simple existencia, no nos es otorgada, sino que es el resultado de la organización humana, en tanto que resulta guiada por el principio de la justicia. No nacemos iguales; llegamos a ser iguales como miembros de un grupo por la fuerza de nuestra decisión de concedernos mutuamente derechos iguales. (Arendt, 1998, pág. 251)

Lo que los gobiernos totalitaristas hacen a las personas refugiadas, asiladas o en situación de exilio, es precisamente ese despojo de derechos, no permitirles tener la posibilidad de acceder a derechos.

La postura de Arendt sobre este derecho a la igualdad o derecho a tener derecho, ha recibido profundos análisis así como críticas en su planteamiento universal y aplicable a los derechos humanos (Cristóbol, 2014), empero, nos permite tener un panorama sobre el reto al que se enfrentan personas que no están en su país de origen para el ejercicio de sus derechos humanos, tales como la ciudadanía, pertenencia, identidad, nacionalidad o cualquier otro derecho político o civil, y así poder identificar todo el cúmulo de violaciones a los mismos en perjuicio de las personas que están en situación de exilio. 
Se han estudiado brevemente tres derechos que son afectados en una situación de exilio: derecho a la información, derecho a la verdad y el derecho a tener derechos, con lo cual podemos considerarlo como una violación sistemática a los derechos humanos. Con todo lo anterior, cabe entonces preguntarse sobre la necesidad de una propuesta específica para atender a las personas que están en una situación de exilio, objetivo que será estudiado en el último apartado de esta investigación.

\section{$¿$ Es necesaria una propuesta legislativa mexicana para atender el exilio?}

Como se ha visto, existen divergencias en la forma en la cual entendemos el exilio, lo cual depende de la perspectiva desde la cual se estudie. La propuesta es que, desde el ámbito jurídico, se le considere como una violación sistemática a los derechos humanos. Al principio de este trabajo planteamos la siguiente interrogante: en México, ¿se debería legislar para atender una violación a los derechos humanos como es el caso del exilio? Adelantamos la respuesta: sí. Se considera de capital importancia no solo plantear un cuerpo normativo que pueda dar respuesta a esta violación a los derechos humanos, sino que sirva para la planeación y ejecución de políticas públicas para atender a las víctimas que se encuentren en esta situación.

Se tomarán algunos elementos de otras legislaciones como la española, chi- lena y argentina, que indirecta o directamente han intentado atender a las víctimas del exilio, a fin de contar con puntos de coincidencia y aprendizaje para su integración en un cuerpo legislativo en México.

Es de suma importancia retomar el bagaje histórico de las normatividades mencionadas por el profundo simbolismo que implica legislar sobre hechos tan importantes para la construcción de la vida pública de una nación.

El llamado "Exilio Republicano Español”, ocurrido entre 1936 a 1939, debido a la Guerra Civil Española, tuvo como consecuencia que una gran cantidad de ciudadanos migraran hacia otros países a fin de resguardarse y esconderse por las posibles represalias que surgieran por el conflicto en el que se encontraba su país.

Años posteriores, y en atención al impacto cultural, histórico, social y político, así como el fin de la dictadura, y en aras de consolidar un proceso de reconciliación del Estado con los exiliados españoles, se hizo necesario plantear un adecuado marco jurídico para atender a las personas que en su momento se encontraron en situación de exilio y que volvieron a España ya bajo un régimen democrático.

Así surgió la denominada Ley 52/2007, o Ley de Memoria Histórica Española, cuyo objetivo, de acuerdo con su artículo primero, era: "reconocer y ampliar derecho a favor de quienes padecieron persecución 
o violencia, por razones políticas, ideológicas o de creencia religiosa, durante la Guerra Civil y la Dictadura, promover su reparación moral”, esta ley no expresa de forma explícita quiénes son o quiénes fueron personas exiliadas, no obstante, podemos entender que esta ley es un primer paso para atender a las personas que en su momento padecieron una situación de exilio. Un ordenamiento anterior, la Ley 40/2006 del Estatuto de la ciudadanía española en el exterior, era más claro en relación con el exilio. La doctora Nuria González Martín lo señala de la siguiente manera: "hace un reconocimiento expreso de aquellos que se vieron obligados al exilio como consecuencia del franquismo" (2008, pág. 989).

Ahora bien, esta Ley de Memoria Histórica Española ha tenido múltiples críticas, por ejemplo, se habla de una reparación moral y económica para las personas que sufrieron persecución política durante la dictadura de Francisco Franco, pero sin consecuencias penales para quienes ordenaron el exilio (Cajiao, 2008). En este sentido, se considera que existe esa preocupación sobre lo que fue el exilio español, así como sus repercusiones políticas y jurídicas; no obstante, la política de atención para las personas en situación de exilio estuvo encaminada a una atención de personas con necesidades de protección internacional, en otras palabras, personas solicitantes del reconocimiento de la condición de refugiado.

En el caso de Argentina, también existen ordenamientos legales que permiten al Estado tener un marco de actuación a fin de atender a las personas que han sido víctimas del exilio o de sus consecuencias. Para Argentina, la década de los setenta fue sumamente trágica y dolorosa, con el arribo de la Alianza Argentina Anticomunista y posteriormente la Junta Militar, así como el comienzo de desapariciones forzadas, tortura y detenciones arbitrarias. En el caso de la legislación de Argentina, incluso se puede encontrar una variante sobre el exilio: el autoexilio voluntario. Esto nos recuerda lo planteado en la primera parte de este trabajo sobre considerar el exilio como un derecho o una opción:

en la jurisprudencia nacional se ha verificado una clara doctrina judicial por exilio forzoso en el sentido de la admisión del régimen reparatorio previsto en la Ley No. 24,043, en aquellos casos debidamente probados y precedidos por situaciones de detención ilegal y/o persecución que hubieran generado en los involucrados un temor fundado a experimentar un grave riesgo en sus vidas, integridad física y/o libertad personal y no para los casos en donde es posible interpretar la partida del país como un autoexilio voluntario (Comisión Intera- 
mericana de Derechos Humanos, 24 de octubre de 2019, pág. 3).

Esta distinción entre "exilio forzoso" y "autoexilio voluntario" repercute en la operatividad de la legislación argentina, toda vez que es indispensable precisar la terminología para acceder a los recursos e indemnizaciones que la ley correspondiente prevé. Por otro lado, la experiencia en Chile fue igual de compleja que con el resto de los países de sudamérica que padecieron las consecuencias de gobiernos militares: golpes de Estado, desapariciones forzadas, violaciones a los derechos humanos, y por supuesto, personas en situación de exilio. Luego del golpe de Estado en 1973, el tema del exilio fue recurrente, incluso se extendió más allá del final de la dictadura, lo que permite estimar que un millón de chilenos vivían fuera de su país para el año 2003 (Norambuena, 2008, pág. 166).

La base legislativa que Chile usó para la atención de todas las personas que vivieron el exilio, es decir, para las víctimas, fue la Ley 18994, promulgada en 1990. Con esta se creó la Oficina Nacional de Retorno, la cual tenía entre sus funciones y atribuciones "estudiar, proponer e impulsar la aplicación de planes, programas y proyectos dirigidos a facilitar la reinserción social de los exiliados que tengan o hayan tenido la nacionalidad chilena, así como de los hijos nacidos en el extranjero de padre o madre exiliados que sean o hayan sido chilenos, que retornen o hayan retornado al territorio nacional".

Uno de los aspectos de la legislación chilena es que sí determina y delimita a quiénes debemos considerar como personas exiliadas. Así lo señala en su artículo 2, inciso a) en una definición y caracterización si bien extensa, muy enriquecedora para la discusión jurídica:

Para los efectos de esta ley, se consideran exiliados las personas condenadas a penas privativas de la libertad que obtuvieron la conmutación de esas sanciones por la de un extrañamiento (...), las expulsadas $\mathrm{u}$ obligadas a abandonar el territorio nacional por resolución administrativa; las que luego de viajar normalmente al extranjero, fueron objeto de prohibición de reingresar a Chile; aquellas que buscaron refugio en alguna sede diplomática, siendo posteriormente transferidas al extranjero; quienes, en el extranjero, se acogieron a la Convención sobre el Estatuto de los Refugiados, de Naciones Unidas, en los países de acogida, refugio de carácter humanitario; las personas que se vieron forzadas a abandonar el país debido a la pérdida de su trabajo por motivos políticos y luego sufrieron la prohibición de ingresar al país. 
Se puede apreciar que el componente común en las características de las personas en situación de exilio es la prohibición expresa para ingresar al país. Si bien la Ley 18994 pudo considerar a personas exiliadas, a las mismas que se acogieron a la Convención sobre el Estatuto de Refugiados o Convención de Ginebra de 1951, no deja de insistir en el hecho expreso de que el Estado en un momento prohibió el ingreso o regreso de estas personas. De igual manera, recoge el aspecto de conmutación de la pena al poner al exilio como una alternativa a alguna sanción.

Consideramos que la Ley 18994 de Chile buscó construir, desde el derecho, las características jurídicas para la atención integral de las víctimas del exilio. No obstante, también guarda otra característica particular: la temporalidad para la reparación del daño. Apenas con 11 artículos, la Ley 18994 de Chile, que creó la Oficina Nacional de Retorno para atender a las personas en situación de exilio, señaló que quienes podían beneficiarse por la misma tenían como plazo el 31 de diciembre de 1993, según se lee en su artículo segundo transitorio. De igual manera, la Oficina Nacional de Retorno se extinguiría por ministerio de ley a partir del 20 de septiembre de 1994, como se lee en su artículo 11.

La ley chilena delimita en una temporalidad concreta el acceso a la justicia para las personas en situación de exilio, esto deviene en una complejidad difícil de entender y estudiar. En líneas anteriores apuntamos que para el año 2003 había aproximadamente un millón de personas chilenas viviendo en el extranjero, cuando la Oficina Nacional de Retorno ya llevaba diez años extinguida. La pregunta pertinente es: ¿cuánto tiempo debió existir la Oficina Nacional de Retorno para la atención de las personas chilenas en exilio? ¿Se debe mantener una política o ley permanente para la atención de víctimas del exilio? ¿Delimitar temporalmente el acceso a la justicia y a la reparación del daño de las víctimas del exilio en Chile es acorde con una perspectiva de derechos humanos? Todas estas son interrogantes válidas y cuya respuesta no podemos proporcionar en este momento, empero, se considera que el hecho de que existan esfuerzos desde el derecho por atender a las personas en situación de exilio, con sus limitantes e interrogantes, implica acercarnos a una efectiva tutela con perspectiva de derechos humanos para las víctimas.

Una vez que hemos tenido un breve desglose de los ordenamientos legales en materia de derechos humanos que han tenido el objetivo de atender directa o indirecta, implícita o explícitamente a las personas en situación de exilio, hemos podido apreciar lo complejo de consolidar como tal una "ley de exilio" o "ley para atender a las personas en situación de exilio", ¿por qué en México no ha sido necesaria una ley que de forma explícita señale o regule 
la política pública para atender a las personas que se encuentran o se encontraron en esta condición de vulnerabilidad? ¿es suficiente con la base legal que tenemos en la Ley sobre Refugiados, Protección Complementaria y Asilo Político?

Si vemos el artículo 11 de la Constitución Política de los Estados Unidos Mexicanos, incluso se puede apuntar que tanto el refugio como el asilo político constituyen un derecho constitucional, incluso hay quienes piensan que elevar a rango constitucional la figura jurídica de asilo y refugio, ha sido un reconocimiento a la larga tradición que México ha tenido al recibir a personas extranjeras que han sido perseguidas políticas en sus países, o que vienen huyendo para proteger sus vidas, así como poner la legislación nacional de acuerdo con parámetros internacionales: "Uno de los signos de esta reforma es precisamente la vocación de insertar a México en los parámetros internacionales de protección de los derechos fundamentales" (Carbone1l, 2012, pág. 101).

En el caso de México, el exilio se ha caracterizado no porque exista un gran número de personas mexicanas en situación de exilio, sino porque México, en diferentes momentos de su historia, ha recibido a personas en situación de exilio.

Ahora bien, la atención en México a personas en situación de exilio provenientes de España, Chile o Argentina se basó principalmente en la idea de que eran refugia- dos: "Entre los exiliados de mayor edad, está presente la solidaridad mexicana a los refugiados de la Guerra Civil española, así como la posición de México frente a la Revolución Cubana” (Yankelevich, 2018, pág. 34). Tenemos entonces que el "refugio" como categoría jurídica ha subsumido de tal manera al exilio, e incluso a otras categorías de la movilidad humana como las personas apátridas o desterradas, ya que no se ha discutido la posibilidad de incluir una legislación específica para atender los casos de exilio.

Actualmente no existen datos oficiales sobre el número de personas en situación de exilio que han ingresado a territorio, tampoco hay datos públicos de personas en situación de exilio. Es de capital importancia advertir que para las mismas autoridades mexicanas competentes (Secretaría de Relaciones Exteriores, Secretaría de Gobernación, Instituto Nacional de Migración, Comisión Mexicana de Ayuda a Refugiados) no es posible determinar y delimitar las competencias correspondientes, en el marco de sus atribuciones, para atender a las personas en situación de exilio.

El 4 de mayo de 2021 se realizaron solicitudes de acceso a la información pública, a través de la plataforma "Infomex", a la Secretaría de Gobernación, Secretaría de Relaciones Exteriores, al Instituto Nacional de Migración y a la Comisión Mexicana de Ayuda a Refugiados, a fin de obtener 
una respuesta oficial sobre el número de personas en situación de exilio en México. Planteamos la siguiente pregunta:

¿Cuántas personas exiliadas o en situación de exilio han ingresado a México desde el año 2011? Desglosar información por género, nacionalidad, edad y mes.

Las respuestas que obtuvimos por parte de las autoridades federales fueron las siguientes:

1) Repuesta de la Secretaría de Relaciones Exteriores contenida en la Plataforma Nacional de Transparencia:

Estimado solicitante: Esta Secretaría no es competente para atender su petición, toda vez que es el Instituto Nacional de Migración (INM) quien se encarga de instrumentar la política migratoria en territorio nacional, además de tramitar y resolver sobre la internación, estancia y salida del país de los extranjeros, de conformidad con lo establecido por el artículo 20 de la Ley de Migración, misma que puede ser consultada en la siguiente liga electrónica: https://cis.org/sites/cis. org/files/Ley-de-Migracion.pdf Derivado de lo anterior, se sugiere dirigir su solicitud al INM a través de la Plataforma Nacional de Transparencia (PNT), o bien, directamente en su Unidad de Transparencia, ubicada en: Homero 1832, Col.
Los Morales Polanco, Alcaldía Miguel Hidalgo, Ciudad de México, México, C.P. 11510, o a los teléfonos (55) 53872400 Ext. 18229 o al correo: rleon@inami.gob. $\mathrm{mx}$. Asimismo, la Coordinación General de la Comisión Mexicana de Ayuda a Refugiados (COMAR) órgano desconcentrado de la Secretaría de Gobernación (SEGOB), es responsable de conducir la política en materia de refugiados y protección complementaria, de conformidad con el artículo 2, inciso C, fracción V, 99 y 100 del Reglamento Interior de la SEGOB, mismo que puede ser consultado en la siguiente liga electrónica https:// www.gob.mx/cms/uploads/attachment/ file/211034/20_Reglamento_Interior_ de_la_Secretar_a_de_Gobernaci_n.pdf. En este sentido, la COMAR puede contar con información de su interés, por lo que podrá realizar su consulta, a través PNT, o directamente en su Unidad de Transparencia, ubicada en: Versalles 49, interior 5, Col. Juárez, Alcaldía Cuauhtémoc, Ciudad de México, C.P. 06600, o al teléfono 52098800 Ext. 30146 y 30138, o al correo electrónico: uecomar@segob. gob.mx. Para cualquier duda y/o comentario al respecto, podrá comunicarse al teléfono 36865023 ext. 5308 con los últimos seis dígitos de su folio, dónde con gusto le atenderemos. Atentamente. La Unidad de Transparencia. 
Como se puede apreciar, la Secretaría de Relaciones Exteriores no tiene claridad sobre qué autoridad es la competente para atender a las personas en situación de exilio, ya que orienta para que se realice la solicitud de información ya sea al Instituto Nacional de Migración o a la Comisión Mexicana de Ayuda a Refugiados; la primera como encargada de documentar el ingreso y egreso de personas extranjeras, y la segunda, en su carácter de autoridad administrativa encargada de conducir la política pública en materia de refugio, asilo y protección complementaria. Sin embargo, como tal, no existe una autoridad determinada como competente para llevar a cabo la política de atención a personas en situación de exilio.

2) Respuesta de la Secretaría de Gobernación contenida en el escrito sin oficio correspondiente a la solicitud de transparencia 400121921:

Lo anterior, toda vez que, del análisis de las atribuciones previstas en el Reglamento Interior de la Secretaría de Gobernación, no se desprenden elementos que apunten a la presunción de existencia de la información solicitada en alguna de las Unidades Administrativas que integran este Sujeto Obligado. No obstante, en vía de orientación y sin prejuzgar la existencia de la información, y en base a los elementos que usted mismo propor- ciona en su solicitud, se sugiere dirigir su solicitud de información a la Secretaría de Relaciones Exteriores (SRE) por ser el sujeto obligado que, en el ámbito de sus atribuciones y competencias, podría tener información al respecto.

La respuesta de la Secretaría de Gobernación sugiere que es la Secretaría de Relaciones Exteriores la que podría tener la información que se busca, con base en sus atribuciones y competencias. No obstante, no señala el fundamento legal correspondiente. Cabe señalar que la Secretaría de Gobernación no hace mención ni al Instituto Nacional de Migración ni a la Comisión Mexicana de Ayuda a Refugiados, no obstante que estos órganos desconcentrados pertenecen a dicha Secretaría de Gobernación.

3) Respuesta del Instituto Nacional de Migración, contenida en el escrito sin número de oficio correspondiente a la solicitud de transparencia 0411100036621:

Sobre el particular, en términos de lo establecido en el artículo 130 del Reglamento Interior de la Secretaría de Gobernación, me permito hacer de su conocimiento que la Dirección General de Regulación y Archivo Migratorio no tiene atribuciones, ni información para atender lo requerido. 
En caso particular, el Instituto Nacional de Migración, especifica que no tiene competencia, información o atribuciones sobre información en materia de personas en situación de exilio, y tampoco canaliza u orienta a fin de que el solicitante pueda acceder a la información.

4) Respuesta de la Comisión Mexicana de Ayuda a Refugiados contenida en la solicitud de transparencia de folio 0422000006021:

\section{Secretaría de Relaciones Exteriores.}

Como se puede observar, para la Comisión Mexicana de Ayuda a Refugiados es la Secretaría de Relaciones Exteriores la autoridad competente para atender a las personas en situación de exilio, empero, tampoco hace alusión al fundamento legal o los motivos por los cuales considera el sentido de su determinación.

Vemos entonces que las cuatro autoridades administrativas (Secretaría de Gobernación, Secretaría de Relaciones Exteriores, Instituto Nacional de Migración y Comisión Mexicana de Ayuda a Refugiados) con la encomienda de dirigir y ejecutar la política pública en materia de movilidad humana, no tienen claridad sobre quién o quiénes son competentes para atender a personas en situación de exilio.

En este mismo sentido, merece la atención el hecho de que no exista actual- mente, por parte de la Suprema Corte de Justicia de la Nación, ningún criterio jurisprudencial con relación al "exilio", ni siquiera como tesis aislada. Esto implica que no se ha activado ningún mecanismo de control constitucional con relación a las personas en situación de exilio ante el Poder Judicial de la Federación, ni el juicio de amparo, alguna controversia constitucional o acción de inconstitucionalidad.

Por lo que toca a la justicia administrativa (juicio de nulidad ante el Tribunal Federal de Justicia Administrativa), tampoco se encuentran antecedentes o algún juicio promovido en relación con la figura del exilio. Se hace hincapié en este punto, toda vez que, desde nuestra perspectiva, el exilio sigue sin dimensionarse o entenderse en su esencia jurídica. ¿Bajo qué argumento podemos acudir a buscar la protección de la justicia federal si no sabemos si el exilio es un castigo o un derecho? ¿Cómo podemos promover un juicio de amparo por omisión si no sabemos tampoco cuál de todas las autoridades ha sido omisa en la atención a personas en situación de exilio?

Se considera que las personas refugiadas, asiladas políticas y en situación de exilio, si bien podrían considerarse similares, necesitan atenciones particulares, un enfoque diferenciado para el ejercicio y protección de sus derechos humanos. Por lo tanto, para que la autoridad administrativa pueda llevar a cabo la atención o la 
ejecución de políticas públicas, es importante primero establecer un marco normativo que regule qué autoridad y bajo qué criterios se debe proporcionar atención a las personas en situación de exilio.

\section{Conclusiones}

Es cierto que tenemos todo un cuerpo normativo a nivel nacional e internacional que regula la protección de las personas solicitantes del reconocimiento de la condición de refugiados, pero no se puede olvidar el telón de fondo que almacena la historia de lucha de quienes huyen de guerras y dejan su tierra para llegar a lugares desconocidos, donde además son personas desconocidas, sin patria, sin nombre, sin retorno.

Pareciera que no es necesaria o urgente una "Ley especial para atender a las personas en situación de exilio", debido a la ausencia de datos oficiales. Aunado a lo anterior, puede darse el caso de que las mismas personas no manifiesten estar en condición de exilio cuando entran a otro país, lo que complica todavía más los registros sólidos sobre esta vertiente de la movilidad humana.

Toda la información que se tiene de manera histórica son estimaciones o datos aportados por otros países. De igual manera, no se no se sabe si existen ciudadanas y ciudadanos mexicanos exiliados, es decir, que el gobierno de México haya impuesto a manera de penalidad el exilio a alguna persona por motivos políticos o de cualquier índole. Sin embargo, sí es importante considerar un capítulo especial en la Ley sobre Refugiados, Protección Complementaria y Asilo Político que pueda especificar y dar un soporte jurídico robusto y completo a la figura del asilo a partir de los lineamientos internacionales.

La autoridad competente para atender a las personas en situación de exilio, en armonía con lo expuesto en el cuerpo del presente trabajo, tendría que ser la Comisión Mexicana de Ayuda a Refugiados, órgano desconcentrado de la Secretaría de Gobernación, por su naturaleza y mandato de ley conferidos para atención y ejecución de política pública sobre refugio y asilo político, además de la canalización y orientación de ayuda humanitaria. No así el Instituto Nacional de Migración, cuyo mandato se orienta más sobre regularización migratoria.

Es pues necesaria una adición a la Ley sobre Refugiados, Protección Complementaria y Asilo Político, para que un capítulo especial determine la naturaleza jurídica del exilio, sus alcances, la autoridad competente, los lineamientos de política pública para la atención de las personas que se encuentran en esta situación de vulnerabilidad, así como sus claras diferencias con el refugio y el asilo político. Para tales efectos puede ser conveniente aprender de las experiencias en España, 
Chile y Argentina, en donde retomemos la atención integral, el acceso a los derechos fundamentales, protección internacional y facultades bien delimitadas para la Comisión Mexicana de Ayuda a Refugiados.

Esta reforma en materia de exilio llevaría la tradición humanitaria de México, más acorde con legislaciones internacionales, las cuales sí contemplan diferencias entre el exilio, refugio y asilo político. De esta manera, se visibiliza a un sector vulnerable de la población que ha navegado en el limbo jurídico, sin tener certeza sobre sus derechos o autoridad a la cuál acudir en caso de encontrarse en una situación de exilio.

Entonces, proponemos una legislación que atienda a las personas que son condenadas al exilio y que llegan a nuestro país buscando protección jurídica y ayuda humanitaria.

De acuerdo con lo asentado en el presente trabajo, se considera que existen diferencias históricas, epistemológicas y jurídicas entre el refugio, el asilo político y el exilio. Incluso, queda pendiente el análisis de otras figuras clave en los discursos y estudios sobre la movilidad, como el desplazamiento forzado interno o el destierro. Estos vacíos epistemológicos en la literatura jurídica son los que impiden tener claridad en el momento de legislar sobre alguna temática en particular, como lo es en este caso el exilio. De aquí la importancia de continuar con estas discusiones te- máticas que podrían tener un impacto en el ámbito legislativo y en el ejercicio de los derechos humanos.

\section{Referencias}

Abrao, P., Mersky, M., Meregali, K., Morin, S., \& Rice, J. (2013). En busca de la verdad. Elementos para la creación de una comisión de la verdad eficaz. Brasilia: Comisión de Amnistía del Ministerio de Justicia de Brasil.

Agamben, G. (1996). Política del exilio. Barcelona: Cuadernos de crítica de la cultura.

Alto Comisionado de las Naciones Unidas para los Refugiados. (2011). Manual y directrices sobre procedimientos y criterios para determinar la condición de refugiado. Ginebra: ONU.

Amaya Villarreal, Á. F. (2007). "Efecto reflejo”: la práctica judicial en relación con el derecho a la verdad en la jurisprudencia de la Corte Interamericana de Derechos Humanos. International Law: Revista Colombiana De Derecho Internacional, 131152.

Arendt, H. (1998). Los orígenes del totalitarismo. Madrid: Taurus.

Arendt, H. (2017). En el presente. Ensayos políticos. Barcelona: Página Indómita.

Benhabib, S. (2004). Los derechos de los otros. Extranjeros, residentes y ciudadanos. Barcelona: Gedisa. 
Cajiao, E. (2008). La recepción de la ley de la memoria histórica en España. Análisis Político, 51-58.

Carbonell, M. (2012). Los derechos humanos de libertad de tránsito, asilo y refugio. En D. Cienfuegos Salgado, \& G. Froto Mandariaga, Los derechos humanos en el momento actual (págs. 79-107). México: Universidad Autónoma de Coahuila, Poder Judicial del Estado de Coahuila, Editora Laguna.

Cecilia Ávila, M. (2018). La excepcionalidad jurídica del exilio. Un acercamiento a la expulsión punitiva de las dictaduras militares chilena y argentiva. Las Torres de Lucca. Revista Internacional de Filosofía Política, 69-102.

Centro de Derechos Humanos, Miguel Agustín Pro Juárez, A.C. (diciembre de 2018). Manual sobre documentación de violaciones a los derechos humanos. Obtenido de Centro ProDH: https://centroprodh. org.mx/wp-content/uploads/2019/05/ ManualDocumViolDH.pdf

Comisión Interamericana de Derechos Humanos. (24 de octubre de 2019). Informe No. 221/19. Admisibilidad. Francisco Pompeyo Ramos Marrau. Argentina. OEM. Cristóbol, M. (2014). Variaciones posmarxistas sobre "el derecho a tener derechos" de Hannah Arendt . Revista de Derechos Humanos y Estudios Sociales, 145-166.

Derecho humano de acceso a la información. (2015). Ciudad de México: CNDH-Institu- to Nacional de Estudios Históricos de las Revoluciones de México.

Gianoglio Pantano, L. M. (2012). Los exiliados en La Justicia Transicional argentina: Una aproximación a perspectivas y debates respecto al exilio. I Jornadas de Trabajo sobre Exilios Políticos del (págs. 1-18). La Plata: UNLP-FAHCE.

González Martín, N. (2008). Ley de Memoria Histórica Española. Ley 52/2007, de 26 de diciembre, por la que se reconocen y amplían derechos y establecen medidas a favor de quienes padecieron persecución o violencia durante la Guerra Civil y la dictadura. Boletín Mexicano de Derecho Comparado, 979-991.

Grinsvall, S., \& Lora Fuentes, M. E. (2012). La experiencia del exilio político y sus consecuencias en la subjetividad. Ajayu, 172-185.

Gros Espiell, H. (26 de 03 de 2021). Corte Interamericana de Derechos Humanos. Obtenido de https://www.corteidh.or.cr/ tablas/a12007.pdf

Leonardo Franco (Coord.). (2004). El asilo y la protección internacional de los refugiados en América Latina: Análisis crítico del dualismo "asilo-refugio" a la luz del Derecho Internacional de los Derechos Humanos. San José: ACNUR.

Martínez, N. B. (2012). Asilo, Refugio y Exilio. Perspectivas de las Ciencias Económicas y Jurídicas, 203-223. 
Norambuena, C. (2008). El exilio chileno: río profundo de la cultura en iberoamérica. Sociohistórica, 163-195.

Petro González, I. R., \& Naranjo Tabares, D. (2020). El Estado como garante del derecho de las víctimas a la verdad en Colombia. Pensamiento Americano, 152-162.

Secretaría de Relaciones Exteriores. (Julio de 2016). Relaciones Exteriores. Extranet. Obtenido de https://extranet.sre.gob. $\mathrm{mx} /$ images/stories/asilo/asilo2016.pdf

Straehle, E. (2018). Europa frente a los refugiados: reeler los derechos humanos desde Hannah Arendt. Lectora. Revista de dones i textualitat, 61-81.

Torres Aguilar, M. (1994). La pena del exilio: sus orígenes en el derecho romano. Anuario de historia del derecho español, 701-786.
Yankelevich, P. (2018). Exilios: México en la memoria latinoamericana. En E. Díaz Silva, A. Reimann, \& R. Sheppard, Horizontes del exilio. Nuevas aproximaciones a la experiencia de los exilios entre Europa y América Latina durante el siglo XX (págs. 19-48). Madrid: Iberoamericana.

Legislativas

México: Ley sobre refugiados, protección complementaria y asilo político. Última reforma incorporada: 11 de noviembre de 2020 (México), 11 noviembre 2020, disponible en esta dirección: https:// www.refworld.org.es/docid/5fae21fe4. html (último acceso el 26 marzo 2021).

España: Ley 52/2007: 26 de diciembre de 2007 (España), disponible en esta dirección: https://www.boe.es/buscar/ 
pdf/2007/BOE-A-2007-22296-consolidado.pdf (último acceso el 14 de junio de 2021)

Chile: Ley 18994: 20 de agosto de 1990 (Chile) disponible en esta dirección: https:// www.bcn.cl/leychile/navegar?idNorma=30362 (último acceso 14 de junio de 2021) 